\title{
Does the Patient Clinical Complexity Level (PCCL) reflect nursing acuity? John Bayliss-McCulloch
} Address: Senior Project Officer, Funding, Health \& Information Policy Branch, Metropolitan Health \& Aged Care Services, Department of Human
Services, Victoria, Australia

Email: John Bayliss-McCulloch - John.Bayliss-McCulloch@dhs.vic.gov.au

from 23rd Patient Classifications Systems International (PCSI) Working Conference

Venice, Italy. 7-10 November 2007

Published: 26 November 2007

BMC Health Services Research 2007, 7(SuppI I):AI4 doi:I0.II86/I472-6963-7-SI-AI4

This abstract is available from: http://www.biomedcentral.com/I472-6963/7/SI/AI4

(C) 2007 Bayliss-McCulloch; licensee BioMed Central Ltd.

\section{Background}

Approximately $30 \%$ of inpatient costs relate to nursing care. Many hospitals are relinquishing their use of patient dependency systems following the introduction of ratio based nursing awards and the omission of this functionality from replacement computer systems architecture. Ratcliffe* has proposed a PCCL adjusted bedday and activity model for the allocation of nursing costs. (*Ratcliffe, Kevin; Clinical Costing of Nursing Activity - Benchmarking Project.)

\begin{abstract}
Aims
To examine the relationship between Patient Clinical Complexity Level (PCCL) and nursing activity/cost as measured by patient dependency scores, and therefore ascertain the suitability of the PCCL as a patient dependency surrogate.
\end{abstract}

\section{Method}

Patient dependency, length of stay, transfer, and nursing cost data were extracted from the Royal Women's Hospital patient costing system, and nursing costs allocated to patients according to their individual patient dependency scores. Costs relating to 6 Patient Care Areas [PCAs] (3 general wards, ICU, surgical, \& oncology wards) wholly costed by the existing patient dependency data were examined. Investigation into the relationship between PCCL scores, length of stay, and acuity was undertaken by plotting case frequency by LOS and PCCL, and by depicting total and daily cost variability by PCCL using box plot techniques. Variability of average daily cost by PCCL across DRGs was illustrated in graphical form.

\section{Data}

In 2005/6, the Royal Women's Hospital treated 32,673 patients. 18,169 cases were subsequently identified as being treated within the 6 patient care areas under investigation (representing 21,015 case/PCA splits) and were further trimmed to 18,127 cases (total cost $<\$ 100,000$, daily cost $<\$ 2,500)$. Nursing costs for these areas totalled $\$ 29.1 \mathrm{M}$ and were allocated across 895 service codes (allocation types) representing approximately 464,000 allocation items.

\section{Results}

Analysis of total cost by PCCL across the targeted costed population base revealed a correlation of $\mathrm{r}^{2}=0.1157$ and the PCCL/Length of Stay relationship showed a similar correlation of $\mathrm{r}^{2}=0.1206$. The daily cost/PCCL relationship was insignificant at $\mathrm{r}^{2}=0.0223$, though correlation of the median daily cost was significant at $\mathrm{r}^{2}=0.9117$. Results of further analysis of daily costs by PCCL within each Patient Care Area were inconsistent.

To eliminate the potential confounding influence of relatively fixed high nurse/patient ratios within the ICU area and the uncertain clinical relevance of unqualified newborns ${ }^{1}$, these cases were excluded to produce a new costed population comprising 12,689 acute cases. The revised total cost/PCCL correlation improved to $\mathrm{r}^{2}=$ 0.1525 and the PCCL/Length of Stay relationship 
increased further to $\mathrm{r}^{2}=0.1638$. However, the daily cost $/$ PCCL correlation remained insignificant at $\mathrm{r}^{2}=0.0079$ while the median cost relationship deteriorated to $\mathrm{r}^{2}=$ 0.3856 in a negative direction.

\section{Conclusion}

These results suggest that length of stay rather than nursing intensity increases with PCCL. Furthermore, the inconsistency of the PCCL cost relationship across DRGs does not support the use of the PCCL as a global measure of nursing acuity.

Publish with Biomed Central and every scientist can read your work free of charge

"BioMed Central will be the most significant development for disseminating the results of biomedical research in our lifetime. " Sir Paul Nurse, Cancer Research UK

Your research papers will be:

- available free of charge to the entire biomedical community

- peer reviewed and published immediately upon acceptance

- cited in PubMed and archived on PubMed Central

- yours - you keep the copyright

Submit your manuscript here:

http://www.biomedcentral.com/info/publishing_adv.asp 